\title{
Qualitative Research in the Journal of Autism and Developmental Disorders
}

\author{
Gerrit lan van Schalkwyk ${ }^{1}$. Jeroen Dewinter ${ }^{2}$
}

Published online: 26 March 2020

(c) Springer Science+Business Media, LLC, part of Springer Nature 2020

JADD is receiving a high volume of submissions describing qualitative research projects. These studies cover a range of critical topics from the perspectives of patients, providers, caregivers and families. We consider the publication of qualitative and mixed methods research to be an important part of the journals mission; at the same time, this has posed new challenges for providing a review process which is both fair to authors, and consistent with the quality standards generally required for research and publication in JADD.

Some research questions can be better answered by qualitative or mixed methods approaches then by quantitative methods. Qualitative methods are relevant when researchers want to explore how people experience situations and problems, giving voice to the lived experience of autistic individuals and stakeholders. Mixed-methods may be suitable when there is a need to assess the generalizability of findings from exploratory studies, or when group level findings need to be explained (Creswell and Plano Clark 2011; Howitt 2010). The need for qualitative studies in research on autism has been stressed as a way to describe a richer perspective into the lived experience of autistic individuals and the people around them (parents, siblings, partners, professionals). This perspective may be particularly informative as it relates to relatively unknown and underexplored themes such as experiences of healthcare, sexuality and employment (Dewinter et al. 2015; George and Stokes 2018; Warner et al. 2018).

Gerrit Ian van Schalkwyk

gerrit_Van_Schalkwyk@brown.edu

Jeroen Dewinter

Jeroen.dewinter@ggze.nl

1 Butler Hospital and Department of Psychiatry and Human Behavior, 345 Blackstone Blvd, Providence, RI 02860, USA

2 GGzE, Centre for Child and Adolescent Psychiatry, and Tranzo Scientific Centre for Care and Wellbeing, Tilburg University, PO Box 909, 5600AX Eindhoven, The Netherlands
The study by Sala et al. (2020) in this edition is an illustration of how qualitative research can offer insight into the experiences of autistic individuals as it relates to romantic relationships and intimacy. The authors analyzed responses from autistic and non-autistic adults and describe similarities and differences pertaining to enablers and barriers to romantic relationships and sex. Their findings offer direction for additional qualitative (e.g. on factors that enable and hinder intimacy) and quantitative enquiry (e.g. comparing the prevalence of these enablers and barriers in larger groups of autistic and non-autistic adolescents and adults).

When considering the value of qualitative studies, attention to methodological rigor is necessary: high-quality qualitative research implies a proper research question (e.g. how do autistic adults experience barriers to enter healthcare), adequate methods to collect and analyze data (e.g. semi-structured interview), sound methodology (e.g. Interpretative phenomenological analysis) and, by preference, an explicit epistemological stance (e.g. phenomenology) (Bolte 2014; Creswell and Plano Clark 2011; Finlay 2011). In addition, awareness about and sensitivity to the needs of autistic participants (Anderson et al. 2018), and stakeholder involvement in the interpretation of rich data provided by autistic participants is important (e.g. see Howard et al. 2019 on participatory research using IPA and Milton et al. 2018 on double empathy).

To be considered for publication in JADD, authors should consider some of the available standards for high quality qualitative research (e.g. Malterud 2001; O'Brien et al. 2014; Riggs 2015) - these offer guidance on how to prepare, conduct and report on qualitative studies. Mixed methods studies need to meet the required standards of rigor typically applied to both qualitative and quantitative manuscripts.

Authors are strongly discouraged from splitting the results of a single qualitative dataset into multiple publications. See Table 1 for a summary of key criteria for qualitative submissions to JADD. Thank you in advance to those authors who 
Table 1 Key criteria for successful submissions of qualitative manuscripts to JADD

\begin{tabular}{|c|c|}
\hline Introduction and literature review & $\begin{array}{l}\text { The literature review should seek to: } \\
\text { - Summarize existing qualitative work in the area } \\
\text { - Summarize key quantitative findings which are relevant to the topic } \\
\text { - Make the case for why the research question is of interest } \\
\text { - Make the case for why a qualitative approach is indicated }\end{array}$ \\
\hline Research question & Clearly defined at outset; specific and relevant \\
\hline Method & $\begin{array}{l}\text { Qualitative studies should almost always rely on one of the three major qualitative methods-semi-structured } \\
\text { interviews, focus groups, or observational studies. Using written responses from surveys is often not a suf- } \\
\text { ficiently robust qualitative method }\end{array}$ \\
\hline Methodology & $\begin{array}{l}\text { The methodology should describe: } \\
\text { - How the interview guide/observational schema was developed } \\
\text { - How a decision was made to define the number of participants or to cease data gathering } \\
\text { - How the sample was recruited and why it was done this way } \\
\text { - How the data was recorded and transcribed, including IRB approval for the procedure } \\
\text { - How analysis was conducted, including the paradigm (e.g., inductive thematic analysis) } \\
\text { - How reliability and validity of the analysis was enhanced } \\
\text { - Where appropriate, description of theoretical framework which informed the analysis } \\
\text { - the researcher's characteristics, context and evidence of reflexivity }\end{array}$ \\
\hline Participants & $\begin{array}{l}\text { The manuscript should include a clear rationale for participant selection (number of participants, character- } \\
\text { istics). Although some paradigms allow a small number of participants, in studies without clear theoretical } \\
\text { frameworks justifying smaller samples, at least } 20 \text { participants should be included to be considered for } \\
\text { JADD } \\
\text { Data from one qualitative sample should be presented in a single, robust manuscript and multiple manuscripts } \\
\text { reporting on analyses from the same qualitative data set will not be considered }\end{array}$ \\
\hline Sensitivity & $\begin{array}{l}\text { The research should ideally be participatory and involve stakeholders in some aspect of the research design } \\
\text { and analysis. Findings that are stigmatizing or may cause harm to the affected community should not be } \\
\text { presented unless the potential value and confidence of the finding exceeds this risk }\end{array}$ \\
\hline Presentation of results & $\begin{array}{l}\text { Results should be presented succinctly, with inclusion of multiple quotes from a range of participants, and be } \\
\text { organized according to the main themes which emerged in the study. The organization of results should not } \\
\text { simply reflect the categories used in the interview guide (which may indicate insufficiently robust analysis) } \\
\text { but rather an emergent framework which best organizes the key perspectives from the study }\end{array}$ \\
\hline Discussion & $\begin{array}{l}\text { The discussion should clearly situate the findings within existing research, as well as describe ways in which } \\
\text { the findings may extend, support, or question existing theory. Practical recommendations are essential }\end{array}$ \\
\hline
\end{tabular}

continue to seek to give voice to autistic adolescents, adults and their families.

Acknowledgments The authors have no specific acknowledgements.

\section{Compliance with ethical standards}

Conflict of interest The authors report no relevant disclosures or conflicts of interest.

\section{References}

Anderson, K. A., Sosnowy, C., Kuo, A. A., \& Shattuck, P. T. (2018). Transition of individuals with autism to adulthood: A review of qualitative studies. Pediatrics, 141(April), S318-S327. https://doi. org/10.1542/peds.2016-4300I.

Bolte, S. (2014). The power of words: Is qualitative research as important as quantitative research in the study of autism? Autism, 18(2), 67-68. https://doi.org/10.1177/1362361313517367.

Creswell, J. W., \& Plano Clark, V. L. (2011). Designing and conducting mixed methods research (2nd ed.). Thousand Oaks: Sage.
Dewinter, J., Vermeiren, R., Vanwesenbeeck, I., Lobbestael, J., \& Van Nieuwenhuizen, C. (2015). Sexuality in adolescent boys with Autism Spectrum Disorder: Self-reported behaviours and attitudes. Journal of Autism and Developmental Disorders, 45(3), 731-741. https://doi.org/10.1007/s10803-014-2226-3.

Finlay, L. (2011). Phenomenology for therapists: Researching the lived world. Chicester: Wiley-Blackwell.

George, R., \& Stokes, M. A. (2018). Gender identity and sexual orientation in autism spectrum disorder. Autism, 11(1), 133-141. https://doi.org/10.1177/1362361317714587.

Howard, K., Katsos, N., \& Gibson, J. (2019). Using interpretative phenomenological analysis in autism research. Autism. https:// doi.org/10.1177/1362361318823902.

Howitt, D. (2010). Introduction to qualitative methods in psychology. Harlow: Pearson Education Limited.

Malterud, K. (2001). Qualitative research: Standards, challenges, and guidelines. Lancet, 358(9280), 483-488. https://doi. org/10.1016/S0140-6736(01)05627-6.

Milton, D., Heasman, B., \& Sheppard, E. (2018). Double empathy. Encylopedia of Autism Spectrum Disorders. https://doi. org/10.1007/978-1-4614-6435-8_102273-1.

O’Brien, B. C., Harris, I. B., Beckman, T. J., Reed, D. A., \& Cook, D. A. (2014). Standards for reporting qualitative research: A synthesis of recommendations. Academic Medicine, 89(9), 1245-1251. https://doi.org/10.1097/ACM.0000000000000388. 
Riggs, D. W. (2015). Ensuring quality in qualitative research. In P. Rohleder \& A. Lyons (Eds.), Qualitative research in clinical and health psychology (First edit) (pp. 57-73). London: Red Globe Press.

Sala, G., Hooley, M., \& Stokes, M. A. (2020). Romantic intimacy in Autism: A qualitative analysis. Journal of Autism and Developmental Disorders. https://doi.org/10.1007/s10803-020-04377-8.

Warner, G., Parr, J. R., \& Cusack, J. (2018). Workshop report: Establishing priority research and well-being of autistic adults and older people. Autism in Adulthood, 1(1), 6-12. https://doi.org/10.1089/ aut.2018.0003.

Publisher's Note Springer Nature remains neutral with regard to jurisdictional claims in published maps and institutional affiliations. 